This item was submitted to Loughborough's Research Repository by the author.

Items in Figshare are protected by copyright, with all rights reserved, unless otherwise indicated.

\title{
Effectiveness, inequality and ethos in three English schools
}

PLEASE CITE THE PUBLISHED VERSION

PUBLISHER

(C) Emerald Group Publishing Limited

VERSION

AM (Accepted Manuscript)

LICENCE

CC BY-NC-ND 4.0

REPOSITORY RECORD

Engel, Laura C., John Holford, and Helena Pimlott-Wilson. 2019. "Effectiveness, Inequality and Ethos in Three English Schools". figshare. https://hdl.handle.net/2134/6173. 
This item was submitted to Loughborough's Institutional Repository (https://dspace.lboro.ac.uk/) by the author and is made available under the following Creative Commons Licence conditions.

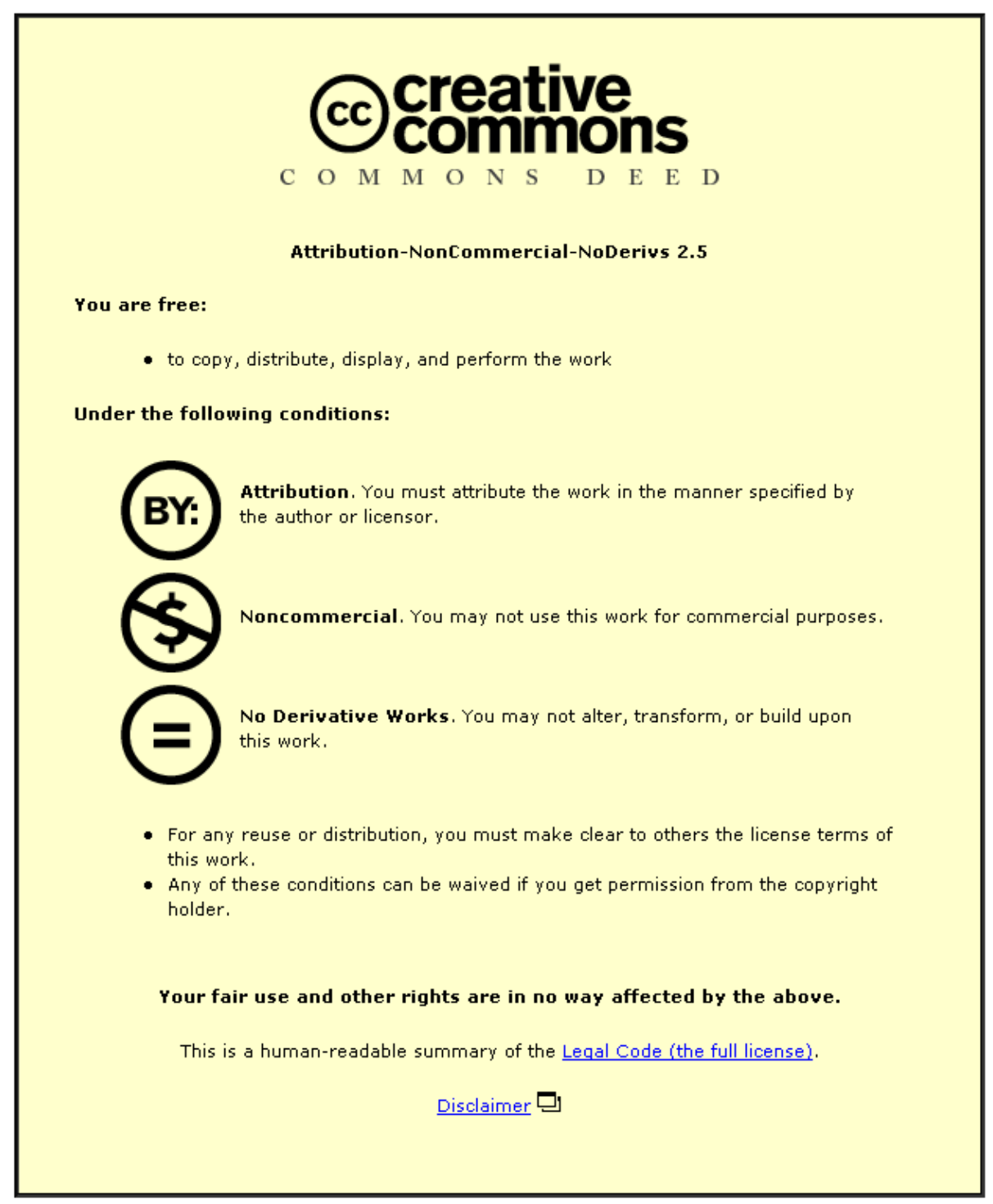

For the full text of this licence, please go to: http://creativecommons.org/licenses/by-nc-nd/2.5/ 


\title{
Effectiveness, inequality and ethos in three English schools
}

\author{
Laura C. Engel \\ Graduate School of Education and Human Development, \\ The George Washington University, USA \\ John Holford \\ School of Education, University of Nottingham, UK \\ Helena Pimlott-Wilson \\ Department of Geography, Loughborough University, UK
}

\begin{abstract}
Many school effectiveness studies have focussed on schools serving disadvantaged communities. 'Schools matter most for underprivileged and/or initially low achieving students. Effective or ineffective schools are especially effective or ineffective for these students' (Scheerens \& Bosker 1997: 96). Analysing how schools can improve in socially disadvantaged communities is essential. The nature of a school cannot, of course, remove social inequality or social exclusion, but it can have a significant positive impact (Sammons 2007). In a study of improving schools in disadvantaged settings, Muijs et al. (2004) found they focus on a number of factors: teaching and learning; enhancing leadership capacity; creating an information rich environment; creating a positive school culture; building a learning community; promoting continuous professional development; involving parents; and engaging external support. This study of three English schools supports Muijs et al.'s findings, but points also to the importance of an 'ethos of inclusion'. It also draws attention to role of schools serving students with Special Educational Needs.
\end{abstract}




\title{
Effectiveness, inequality and ethos in three English schools ${ }^{1}$
}

\begin{abstract}
Many school effectiveness studies have focussed on schools serving disadvantaged communities. 'Schools matter most for underprivileged and/or initially low achieving students. Effective or ineffective schools are especially effective or ineffective for these students' (Scheerens \& Bosker 1997: 96). Analysing how schools can improve in socially disadvantaged communities is essential. The nature of a school cannot, of course, remove social inequality or social exclusion, but it can have a significant positive impact (Sammons 2007). In a study of improving schools in disadvantaged settings, Muijs et al. (2004) found they focus on a number of factors: teaching and learning; enhancing leadership capacity; creating an information rich environment; creating a positive school culture; building a learning community; promoting continuous professional development; involving parents; and engaging external support. This study of three English schools supports Muijs et al.'s findings, but points also to the importance of an 'ethos of inclusion'. It also draws attention to role of schools serving students with Special Educational Needs.
\end{abstract}

\section{Introduction}

In a recent contribution, Normand (2008) explores the emergence of the 'paradigm of school effectiveness' as 'a set of knowledge and stabilised mechanisms for the measurement of education', with research programmes 'strategically positioned ... in terms of access to educational policy-makers' (p. 666). Anglo-American in origin, the school effectiveness approach soon found favour in key international organisations, particularly the Organisation for Economic Co-operation and Development (OECD). During the 1990s, seeking a sound technocratic basis for the gradual extension of its authority in matters educational - its 1995 white paper asserted 'the demise of the major ideological disputes on the objectives of education' (CEC 1995, p. 23) - the European Commission began to move down the same path. Normand argues that the educational indicators adopted under the Lisbon strategy, which 'define the architecture' for education and training programmes in Europe, are 'built on the school effectiveness model' (2008, p. 670).

\footnotetext{
${ }^{1}$ The research for this paper was conducted at the University of Nottingham as part of an Integrated Project 'Strategies for Inclusion and Social Cohesion in Europe from Education' (Includ-ED) funded under the European Commission's $6^{\text {th }}$ Framework research programme (CIT4-CT-2006-028603), and co-ordinated by the University of Barcelona.
} 
As one of its principal exponents acknowledges in a recent report, however, school effectiveness research has been far from uncontroversial. Critics, she points out, have attacked it as paying scant attention to 'theoretical concerns and the influence of social structure'. It rests, they suggest, on an 'ideology of social control', has a 'narrow and mechanistic view of educational outcomes and processes, fosters a culture of "blaming" schools for failing their students and downplays the importance of social class as a determinant of student achievement' (Sammons 2007, p. 9). This is not, of course, merely a theoretical or methodological critique. It is also a critique of the outcomes-based policies and measurement tools introduced over recent decades: these are seen at the same time as essential premises of school effectiveness research, and as its products. For example, increased testing had 'particularly negative' effects for ethnic minority and working class students, while 'narrowing curriculum as well as reducing learning content and instruction to enable student testing had a negative impact, especially on the poorest students' (Normand 2008, p. 668).

This critique has some power: nevertheless, the 'paradigm of school effectiveness' (Normand 2008: 666) defines the reality within which schools in many countries operate. Analysing how schools in socially disadvantaged communities can improve within such policy environment is therefore essential. The nature of a school cannot, of course, remove social inequality or social exclusion, but schools matter: and they 'matter most for underprivileged and/or initially low achieving students. Effective or ineffective schools are especially effective or ineffective for these students' (Scheerens \& Bosker 1997: 96). As Sammons (2007: 21) comments, 'attending an effective school can have a significant positive impact'. In fact, many school effectiveness studies have focussed on schools which serve disadvantaged communities. Muijs et al. (2004) found a number of themes emerging from a review of research on 'improving schools' in 'difficult and challenging circumstances' (p. 149). These were: a focus on teaching and learning, leadership, creating an informationrich environment, creating a positive school culture, building a learning community, continuous professional development, involving parents, and external support and resources. 
The present study was conducted as part of a trans-European research project, Strategies for inclusion and social cohesion in Europe from education (Includ-ED, 2006), funded by the European Union under its Sixth Framework research programme (FP6). While consistently emphasising 'social inclusion' and 'social cohesion', the EU has adopted school effectiveness as part of its educational 'architecture' (Normand 2008: 670). In the spirit of the Lisbon objectives, the Includ-ED project (2006-2011) analyses educational strategies that help overcome inequalities and promote social cohesion. One aim (IncludED 2008) has been to study, across Europe, 'effective' educational practices linked to high rates of educational attainment at different levels of education and programme. The comparative, cross-case analysis of six countries (Includ-ED 2008) provides insight into “"good practices" of inclusive education that are linked to good academic results for all students and [to] the prevention of social exclusion' (p. 3). The project aims to identify 'successful educational strategies ... developed in response to marginalisation and social exclusion' (p. 3) which have relevance regardless of national context.

In order to delve deeper into the issue of inequality and effective educational practice, this paper explores, at the levels of system, school and classroom, strategies identified as 'effective' in generating greater academic attainment and community cohesion in three English schools. In the areas the schools serve, ethnic diversity and social class differences are extensive, social mobility is low, and demands for academic success abound: they therefore provide contexts which allow us to examine critically the potential for specific 'effective practices' to make a positive impact in overcoming inequality (Stoll and Myers 1998). The evidence from our study strongly supports Muijs et al.'s (2004) conclusions. However, it also points to the importance of creating and sustaining an 'ethos of inclusion', and of bringing the study of special education into the school effectiveness literature. Each school worked in dialogue with pupils to construct an inclusive ethos, which became central to the school; and inclusion was more than rhetoric.

\section{Methods}


The Includ-ED project investigated 20 schools across Europe in 2007-2008. These were selected as implementing effective educational practices across different levels (preprimary, primary, secondary) and programmes (vocational training and special education). Case studies of vocational training and special education programmes were not in separate or 'special' schools, but within 'mainstream' (comprehensive) secondary schools. A qualitative case study approach was utilised. The basis for this selection was that schools with high proportions of ethnic minority students with low socio-economic status backgrounds, yet demonstrate successful results, link good academic achievement to inclusive practices (Includ-ED 2006). Twenty schools with high proportions of economically disadvantaged, ethnic minority students were selected across six European countries (Cyprus, Finland, Hungary, Latvia, Spain, United Kingdom). All had records of success in academic attainment, linked to inclusive practices and community participation. The comparative report (Include-Ed 2008) presents cross-national and cross-case findings about effective educational practices. Specifically, the cross-national findings suggest that schools and programmes which utilise practices such as the heterogeneous grouping of students and the use of additional human resources in the classroom have a positive impact on the achievement of disadvantaged groups. Moreover, these practices appear to reduce the achievement gap between groups of students, and to foster an ethos of solidarity and inclusion among the student population; this contributes to overcoming segregation (IncludED 2008).

Three English schools were investigated: one secondary school, one vocational training programme and one special education programme. ${ }^{2}$ The special education programme selected was in a secondary school in which high proportions of students with special educational needs are taught alongside 'mainstream' students (termed 'Special Education'). Each of the schools was located in a socially and economically deprived area, with rising unemployment, and high rates of deprivation, crime and exclusion. A commonlyused UK indicator of students' social and economic background is the proportion who qualify for free school meals. According to the Sutton Trust (2005), roughly $14 \%$ of pupils of the school population in England are entitled to free school meals; the Office for National

\footnotetext{
${ }^{2}$ In order to maintain confidentiality regarding the schools' identity, material (such as Ofsted reports and RAISE online data) are not specifically referenced.
} 
Statistics (2004) classed 'deprived' schools as those where $30 \%$ or more pupils are entitled. School-level data in the selected schools showed the percentage of students eligible to receive free school meals to be considerably higher than the national average. The secondary school and the vocational training programme, for example, had more students eligible for free school meals than $80 \%$ of the schools in the country. Deprivation indices show these schools were among the $20 \%$ most deprived in the country. In 2000 , the area in which the special education school lies was ranked among the $5 \%$ most deprived local authority electoral wards in England, and had a correspondingly high proportion of students (60\%) eligible for free school meals.

Socially and ethnically diverse communities surrounded each of the schools; this was reflected in the schools' populations. When compared to all schools in England, the schools are above the $80^{\text {th }}$ percentile nationally for pupils from minority ethnic groups. In the school selected for the vocational training programme case study, $59 \%$ of students were from ethnic minority groups, whereas the national average for secondary schools in England is $18 \%$. Similarly, in the area of the school selected for the special education programme case study, people came from largely Indian, Pakistan and Black African/Jamaican descent. At this school, over $80 \%$ of the pupils had ethnic minority backgrounds and over two-thirds of pupils speak English as an Additional Language.

Across all schools, the proportion of students with additional needs and/or disabilities was well above national average. According to 2007 data, both the secondary school and vocational training programme had more students with Special Educational Needs (SEN) than $80 \%$ of all schools nationally. The school selected for its special education programme had over $15 \%$ of students with SEN statements in 2007 , a significantly high proportion (DCSF 2005). At each of the schools, the proportion of pupils with and without SEN statements has been rising in recent years.

One of the criteria for selection of the schools was that they had demonstrated success (as defined by students' educational attainment) in relation to their specific context. In other words, students in the selected schools have higher levels of average educational attainment in comparison to students in schools located in similar socio- 
cultural and socio-economic contexts. The Contextual Value Added (CVA) score is used in the UK as an indicator of school performance: it measures pupils' academic attainment and progress in relation to their social context. CVA measures take into account not only attainment but also contextual factors such as gender, SEN, pupil prior attainment, ethnicity, free school meals, first language and different deprivation indicators. Although not problem-free (for instance, it is statistically less reliable for smaller schools, and should not be used to measure an individual school's improvement over time), it is commonly regarded as a fairer measure of school performance than the use of raw outcomes, given the varied levels of attainment that students have when entering school (DCSF 2005). A CVA score of 1,000 is intended to indicate that pupils are attaining results consistent with the socio-economic context of the school's intake. A score above 1,000 signifies that the school's performance overall is better than most schools with a similar student populations and contextual factors, while a score below 1,000 indicates the reverse. On the basis of CVA scores, the case study schools were among the highest performing schools in the country. Each also demonstrated progress over time in their students' academic attainment, as shown in the proportion of students gaining five or more $A^{*}$-C grade GCSEs. (Again, this form of measurement has limitations: the ability of a specific school's entry cohorts may vary from year to year, sometimes significantly; on a national basis, GCSE scores are often criticised as subject to 'grade inflation'.) Although the role of Ofsted inspections has been highly controversial, their reports also suggested the selected schools were performing well in relation to others across the country. Thus in the school studied for its special education programme, for example, the proportion of pupils gaining five or more GCSE grades $A *$ to $C$ had risen each year, very few pupils were leaving without qualifications, and pupils with learning difficulties and/or disabilities also made good progress.

Lastly, the selected schools appeared to each be successful in relation to inclusion and community cohesion. Ofsted inspection reports and awards suggested that each had made to overcome inequality in their local communities, addressing issues of inclusion and community cohesion. For example, one school had achieved an Inclusion Quality Mark (IQM) and numerous other awards. 
The study used a range of methods. Qualitative methods were utilised in order to generate in-depth, descriptive accounts. Semi-structured interviews (Berg 2004) provided a rich and contextual description, providing 'the nuances of increasing complexity' for the elements of the case study (Stake 1995: 21). In addition, 90-minute focus groups were held with teachers and other professional school staff. Before the interviews and the focus groups, participants were provided with a written and oral briefing on the objectives and topics to be covered and how the data would be used (Greenbaum 2000). The focus groups were discussion-based and participant-led in many respects, but prompts were also utilised. Data also were collected by observational methods. For purposes of triangulation, key documents were also analysed (Stake 1995). These included school mission statements and related documents, head teachers' reports to governors, GCSE and GNVQ results, RAISE online and Ofsted reports, school prospectuses and various other data relating to pupil characteristics and community profiles. Table 1 summarises the data sources.

Table 1: Sources of data

Methods

Open-ended interviews

Communicative focus groups

Observations

Collected school documents

\section{Spaces and Participants}

27 in total:

- 12 students

- 6 family members

- 9 school staff (teachers, teaching assistants, specialists, senior management)

3 focus groups (each with 6-10 professionals of the school community)

16 observations (meetings, classroom activities, break-time, spaces of decision-making and community engagement) Mission statements, Ofsted reports, reports to governors, school profile, school improvement 
plan, school prospectus

The interview and focus group data were transcribed verbatim. All names and identifying characteristics were removed or replaced by pseudonyms. Transcriptions were analysed against analysis grids which coded exclusionary and transformative dimensions in the data. The exclusionary dimension refers to any policy, practice or situation that makes academic attainment difficult for students. The transformative dimension relates to transform barriers that make access to social benefits or practices difficult. It includes a contribution to fostering social cohesion and improving the learning process and academic results.

\section{School Effectiveness}

In this section, we argue that our research in three English schools is consistent with the body of research on school effectiveness in relation to social disadvantage. We focus on two themes which emerged strongly in our work: the importance of high expectations, and the development of classroom and school-wide systems to translate these high expectations into practice. We show that these reflect the areas highlighted by Muijs et al. (2004) in their survey of research on improving schools in disadvantaged communities: focus on teaching and learning, leadership, creating an information-rich environment, creating a positive school culture, building a learning community, continuous professional development, involving parents, external support and resources. However, we argue that in schools seeking to serve diverse populations, it is vital these features are accompanied by, and subsumed within, an 'ethos of inclusion'. We also argue that schools serving students with Special Educational Needs should have a more central place in the literature on school effectiveness. In presenting these findings, while there are implications for families and communities, we focus primarily on schools and students.

\section{High Expectations}

In each of the schools, high expectations for the academic attainment of all pupils were expressed, both from the 'top' (for example, upper management) and from the 'bottom' - parents, community members and students. In all cases, high expectations were illustrated in official mission statements, as well as reflected in interviews with school staff and parents. Much of the rhetoric and practice of high expectations has been driven by the school leadership, argued to be second only to teaching as a positive influence on student 
learning (Day et al. 2009). One parent described the secondary school as having an 'ethos where it pushes every child to its full potential' (Secondary School, Parent, Male). Leadership appears to be important (Harris \& Chapman 2001): the head teacher of the vocational training programme described the whole-school ethos as 'can do' (Vocational Training, School Management Staff, Male). Each year, the school continues to set higher and higher targets for GCSE assessment pass rates, which students have continued to meet.

As Sammons (2007) highlighted in her review of school effectiveness literature, 'achievement oriented teachers with high expectations' are highly significant in student achievement (p. 23). During interviews, teachers, management and other staff their schools' reflected an achievement-driven philosophy, expressing genuine beliefs in the ability of all students to be successful. As one teacher remarked, 'everything is focused on achievement' (Secondary School, Teacher, Male). The whole school target was to have ' $90 \%$ of the students to get their five grade A's, A's to C's ... everything is focused on achievement here, getting the best GCSEs they can' (Secondary School, Teacher, Male). Teachers were achievement-oriented, including for students in vocational training programmes. When asked about the academic success of pupils and whether she believed students were going to be academically successful, one teacher exclaimed, 'without a doubt. We're going to beat all records this year!' (Vocational Training, Teacher, Female). As Muijs et al.'s suggest, school effectiveness is aligned with a high level of teacher commitment to quality teaching and learning and to a belief in the value of school interventions in their work with students.

Pupils' parents and family members reflected schools' high expectations for all groups of young people. As one parent of a student in secondary school stated, 'the high expectations are not only geared towards the top sets, but towards all students, and particularly those of disadvantaged backgrounds' (Secondary School, Parent, Female). For children with SEN, a parent commented, 'they work to the best of their ability as does every student in the school and their achievements are celebrated along with everybody else' (Secondary School, Parent, Female). Students were conscious of the ethos of the school and the high expectations that the staff had for each individual: 'they push and even say [if] you're falling back,' said one, 'they'll push you to try and get the best grades out of you that they know that they can' (Secondary School, Student, Female).

Many of the high expectations for students were shown through the belief that all had the ability to go on to further or higher education. This was supported by an 'information-rich' environment permitting detailed tracking of student performance and the gearing of human resources toward pupils' academic needs (Muijs et al., 2004). Our 
secondary school study utilised a data-rich quality assurance system, aimed at ensuring individual student progress. As one parent explained, the school 'put in a system, it goes back to identifying the needs, the learning needs of a student, and they'll put [a] system in place to address the needs' (Secondary, Parent, Female): for example, a learning mentor scheme, or specific classes taught by highly qualified, motivated members of the school management staff (discussed further below).

In each of these schools, systems and mechanisms were in place to assist students with opportunities to continue studying. In each school, every student was given (in the words of one parent)

'a Connexions [educational and careers guidance service] interview, so they're given every single opportunity in order to apply for any outside college that they want to go...They're also offered to come to sixth form, then we do sixth form taster sessions as well to see which courses everybody wants to go on'. (Secondary School, Parent, Female).

Students spoke of presentations from individuals from top universities in the country, and from former students (including those with SEN), who came to discuss university education with students as early as Year 7 . The former students often became role models for current students, reinforcing the schools' message of high aspirations and attainment. Year 9 students were taken to Open Days at different universities in the area. As one teacher stated, 'we're taking them saying, "look this is open to you, these are the options": so it starts from early on' (Secondary School, Teacher, Male). It was often the case that students also had assistance from a tutor with writing their personal statements and filling out college and university applications. Expectations of academic attainment encompassed students with diverse learning and physical disabilities, and those enrolled on vocational courses.

It was common for students in vocational training also to be enrolled in subjects such as mathematics, science and literacy. This approach was designed to increase the skills of young people who had moved away from core academic subjects. There were multiple opportunities for such students to learn about future options, whether by continuing study, or entering the labour market. One student in vocational training, highlighting the high expectations this institution had for young people and the common expectations which were instilled, said, 'they do a careers education and that tells you about how to get a job .... I think they'd prefer us to go on to college' (Secondary School, Student, Female). This school reported that many of the vocational training programme students went on to attend college and/or university. 
Day et al. (2009) point to the key role of leadership in school effectiveness. In the special education programme we studied, the school's management team clearly believed all students could and would perform well academically. One teacher remarked, 'the head teacher believes in inclusion before he believes in anything else, but he believes that every single child should do well, so he's got really high standards' (Special Education, Teacher, Female). The head teacher had 'appointed staff and he has promoted staff that give that same image' (Special Education, Teacher, Female). Each of the schools' leaders maintained that their high expectations for students, as well as the inclusive practices followed at the school, were responsible for the impressive progress each had made over the previous decade. For example, in 2007, 50\% of the Year 11 cohort at the secondary school which had completed its compulsory education two years previously gained admittance to university. This was an exceptional rise: seven years earlier virtually no students from the school had proceeded to higher education.

The impact of an inclusive environment of high academic expectations for all students in each school was also linked to students' possessing greater self-confidence, motivation and high expectations of their own - both for their personal academic progress and for their school. When asked about their future plans, most students said they planned to attend university to study in fields such as education, medicine and forensic science. The school also made efforts to raise parents' expectations of their child's capacity to go to university, regardless of their ability or background. The deputy head commented: 'nobody now turns me down about their child going to college: they used to years ago' (Special Education, Teacher, Female). This has had a positive impact on students' own expectations of their abilities and potential to attend university or enter the labour market. Parents also seemed to reflect this change in their children's expectations: one stated that his children have begun to hold high expectations of their own abilities (Special Education, Parent, Male).

In the special education programme, most students with disabilities continued studying beyond secondary school, with the vast majority going 'into further education and some of them go[ing] into higher education' (Special Education, Teacher, Female). Opportunities for students with SEN included pursuing drama, art and life skills courses (Special Education, Teacher, Female). By providing subjects beyond the standard curriculum, students were able to explore their abilities in other topics; they gained confidence from their success. This achievement translated into an increased belief and faith in their ability to succeed in mainstream curriculum subjects. Only a few students went directly into the labour market after secondary school; the majority attended sixthform college first (Special Education, Teacher, Female). Nevertheless, the school had links 
with organisations to help find students employment. It also provided opportunities for students with SEN to pursue educational opportunities beyond school. These were allocated on an individual basis, depending on each student's particular needs, taking account of their capabilities, interests and limitations (Special Education, Teacher, Female). The school's life skills programme at Year 8 for students with disabilities focused on 'lessons in life skills where we take them out to parks and learn about money ... take them on trips ... we've just took a group to [a local] Market' (Special Education, Teacher, Female). Students who successfully went on to study beyond secondary school often served as role models for the school's younger students (Special Education, Teacher, Female).

\section{Turning Expectations into Practice}

Across all our case studies, participants stressed that the schools did not use these statements of high expectations merely as rhetoric: 'we push the children; we made a commitment to every child' (Vocational Training, School Management Staff, Male). Importance was placed on moving these high expectations for every individual into concrete practice. A head teacher reflected on building this into the systems in place in the school: 'we build vision, rebuild vision, create a mission and embed the mission, into everyday practice' (Vocational Training, School Management Staff, Male). In order to entrench high expectations into school practice, these schools had introduced quality assurance mechanisms and systems for individual student support (cf Hopkins 2001, Joyce et al. 1999). These systems were used to assist every child to make progress, and required operational and strategic planning. Specific and differentiated support was put in place for each student, particularly for students with specific learning needs.

Participants interviewed in our studies typically referred to each student as an individual, with individual learning needs, expressing the need for structures and systems to assist each student's academic needs. For example,

some [students] have higher expectations [of themselves] and just fly through the course and present work as and when it's needed, but others, they can, they'll need the after school club and they'll need homework and they'll need one to ones to actually achieve those same results. (Vocational Training, Teacher, Male)

Each of these schools utilised before and after school homework sessions, revision classes and clubs, as well as 'learning buddies' (pairing an older student with a younger pupil). 
School effectiveness literature shows the links between the broader school community and school improvement (Muijs et al. 2004, Sammons 2007). In our schools, in addition to teaching assistants who provided support in regular classrooms, two of the schools employed learning mentors - often parents or members of the community - who supported students during lessons and gave assistance to classroom teachers. Learning mentors were assigned to students who needed additional support with homework or who had any additional needs, including disabilities. One teacher explained, 'we have a team of mentors, maybe five or six that spread themselves out between probably a fourth of the students that we're saying [are] on the verge of not getting [their] grade C's' (Secondary School, Teacher, Male). These mentors 'help with organisation, getting coursework written up, so there'll be another adult in the [class]room' (Secondary School, Teacher, Male). This serves to support those who would be at risk of underachieving, and to improve the staff:student ratio. One parent, who also served as a learning mentor to students at the school, saw his role as helping the individual student 'to focus, [be] able to work to its full potential, achieving its potential and definitely getting the grade it wants, discussing with the child what it wants to do, where it wants to go ... and trying to keep it focused' (Secondary School, Parent, Male). This variety of forms of support demonstrates the schools' commitment to individualised approaches to learning.

As Sammons (2007) suggests, a positive atmosphere of staff cohesion and cooperation provided resources to more disadvantaged groups of students. One member of staff in the secondary school discussed the positive effects of collaboration between classroom teachers and all support staff. She stated that the school ensures that students achieve good results

because of all the effort that's put in to helping them, it's not just teacher-based, it's like teaching assistants and Learning Mentors and we all work together as a team ... because all the staff work together as a team, they all contribute towards the student's final destination of gaining what they can possibly gain out of it [education]. (Secondary School, Parent, Female)

Teachers often supported one another by assisting in a colleague's classroom during an open period. One teacher stated,

there's also a lot of teacher support, one to one support, in fact all of us regular classroom teachers, if we've got a slightly light timetable we will go into a colleague's class as a support for any pupils that need additional support. (Secondary School, Teacher, Male) 
This teacher for example used his free period during the day to work with several students in another mathematics class. He explained,

I have a free period on my timetable so I've been allocated to work with another maths teacher who has got bottom set Year 8 . There are three or four students with specific learning needs, so I assist perhaps with writing or communication. (Secondary School, Teacher, Male)

This positive use of human resources provided students with individual help, tailored to their own needs. It increased adult-to-student ratios, and also meant that male students had contact with experienced male teachers - helpful in providing positive role models (Carrington and Skelton 2003).

Likewise, the school used its most qualified and experienced teachers in some subject areas to teach the lower sets and thus to target help specifically onto those students who were often most disadvantaged and at risk of school failure. In the case of identified 'at risk' groups in mathematics, both the head and the deputy head, both former mathematics teachers who remained enthusiastic about teaching and the subject, each took a group of these students. As one maths teacher stated, the head teacher would 'take a group that most of us wouldn't be able to teach', and was successful in enabling many of these pupils to achieve Grade C or higher at GCSE (Secondary School, Teacher, Male). This use of experienced teachers with the most at risk students seemed also to transmit and endorse the school's ethos of commitment to the success of each pupil through concrete actions of which students could see themselves as the beneficiaries.

In the secondary school, every Year 10 student also had a personal meeting with a member of the senior management team; Sammons (2007) points to the importance of scuh institutionalization of monitoring systems of individual student progress. In this interview, the aspirations of the students were discussed, as well as their individual progress. A teacher explained the process:

they talk about how they're going to do that year and what they need to do and how they need to achieve and have they got any aspirations. And that usually goes down really well and they really get some focus for the year and you know what they've got to do. So there should be nobody really that hasn't got the guidance really. (Secondary School, Teacher, Female)

For students with disabilities, the school ensured academic progress through a number of practices. The school used 'a lot of planning and preparation' (Special Education, Teacher, 
Female). This had to do both with coursework and examinations. With examinations, the school

make[s] sure that they have the access arrangements for that particular pupil in place for when they sit an exam. For example, some pupils need a reader so we'd have to get permission from the examining board for a reader...some pupils get a scribe, some pupils get extra time, it's whatever is needed to make it, their disability, not a disadvantage really in exams. (Special Education, Teacher, Female)

A support worker at the school said,

we aim to give them the right level of support so that they're not being oversupported and being disabled further, they are being stretched and they continue to develop what skills they have, as well as also to try and engage in as many learning opportunities and even social and sporting activities, to develop you know around their experience. (Special Education, Parent, Male)

The school also had a key worker charged with discussing college arrangements with parents and the family members of pupils with SEN. The key (or support) worker 'tends to go with pupils to different colleges' if necessary, to evaluate the environment for the particular student (Special Education, Teacher, Female). The school also used careers advice and planning services through the government's Connexions programme. A member of the school's management stated that members of the school staff,

will take the children on visits with a support worker to colleges and we will be encouraging the children to ask the right questions about access, but also importantly about support and what they will get. We'll discuss all of that. We will help the children to fill in their own application forms. (Special Education, Teacher, Female)

Our case studies are supportive of the main themes in the literature on the effectiveness of schools in disadvantaged areas identified by Muijs et al. (2004); they are also consistent with Sammons' (2007) conclusions on school effectiveness more generally. High expectations are embedded into successful schools, infusing the school culture and guiding a clear focus on learning and teaching. Information is available, used strategically to guide the development of individual students. Human resources are strategically deployed and developed. The schools operate strongly as learning communities, taking positive and effective steps to involve parents and draw in external support and resources. Leadership is a key factor. Academic attainment is strongly linked to the schools' inclusive ethos. 
Inclusion as an Ethos

Although our findings are consistent in most respects with the existing literature, an important additional dimension emerges from the data. In the schools we studied, values and discourses of inclusion are not the products of leadership and strategy alone: though these are vital. Positive school culture appears in our cases, but what emerges very strongly is the importance of the shared nature of inclusive values: successful inclusive schools have a strong ethos of inclusion. We argue that inclusion, as it relates to educational effectiveness, is much more than a set of strategies or practices. Rather, inclusion appeared to be the central ethos of each school, which it worked to construct in dialogue with pupils, families and surrounding communities. In each of the schools we studied - schools with high ethnic minority populations, and high levels of deprivation - inclusion and inclusive practices reached beyond simple rhetoric and were embodied in shared values and discourses among teachers and students, as well as school managers.

In the school selected for its special education programme, for example, we found evidence of a widespread belief that all individuals have equal value, and that people adults and pupils - should be respectful, one towards another. Leadership clearly mattered in this: principles were laid out in the information sent home to parents and given to pupils to ensure consistency of approach, and the philosophy and ethos of the school were matched by policy and practice. The school had clear behaviour and discipline policies, which set out parents' responsibilities in assisting teachers to uphold the school ethos. Types of unacceptable behaviour were described, as were the procedures to be followed when children contravened rules. This ensured that teachers, pupils and parents were clear about the school's stance before any such issue arose. Parents were also issued with homework booklets, highlighting the role they should play in supporting their child's education. They were expected to read the documents and actively acknowledge that they were aware of the school's policies, in case issues emerged in future. This ethos was supported by the sense of community adopted within the school boundaries, bringing together wider sections of within a society long divided along cultural and religious lines.

Equality of opportunity and discrimination were tackled seriously, preventing any hindrance to pupil progression. The most recent Ofsted full inspection report on this school suggested that pupils were cared for, guided and supported in an 'outstanding' manner. The school prided itself on its success and the inspectors concurred. Given the diversity of needs, abilities and backgrounds, there had been considerable success. What emerges, however, is an ethos in which all individuals were equally valued, and in which all pupils achieved as well as they could. The achievement of all students was celebrated 
through assemblies and a glossy magazine highlighting successes of pupils of all backgrounds and ability levels. Within these, for instance, the progress of asylum seekers was prominent, GCSE results were celebrated, and many students' art productions were displayed. The achievements of pupils in the school sports day were depicted, and there were pictures and results for individuals, both able bodied and disabled.

The inclusive environment in each school was also reflected in students' attitudes toward difference and diversity. In the barrier-free environment of the special educational school, it was rare for students with special needs to be removed from mainstream classrooms. The acceptance of all students demonstrated the equal value placed on all, regardless of background or ability. As an example, one teacher reflected on the comments of an Ofsted inspector to a mainstream pupil after a recent inspection. In class, a SEN pupil's breathing equipment caused noise which the inspector regarded as disturbing. As another (non-SEN) pupil led the inspector to his next class, the inspector remarked on the noise generated in the room by the SEN pupil's equipment. The non-SEN pupil responded sharply that he preferred the noise, as it was crucial to his classmate's well-being and without what the inspector deemed 'noise', the student would not be breathing (Special Education, Teacher, Female). This child's acceptance of the need for a classmate's apparatus, despite the sound disturbance it caused, shows a matter-of-fact recognition of others' needs, and acceptance of difference. A participant pointed out that an inclusive school for students with SEN should provide much more than a physically barrier free setting:

that's the structural part that when people talk about barrier free schools they think that they're talking about access to a lift, ramps, all of those things. You can have a building that is totally physically accessible that excludes you as a person, and then you can have a building which is totally unsuitable where you are included, and we would always go for included rather than just the building. (Special Education, Teacher, Female)

The school had worked to both to construct a physically accessible environment for students with mobility issues, and to be accepting, inclusive and cohesive.

Participants remarked on this school's progress in improving upon inclusion and its success in this area. Through the strategies described above, it seems that inclusion is

about the ethos, it's about the philosophy, it's about the basic belief of every person that equality really is important and that you can't say you're going to have equality of opportunity and then not put in place all the structures to give 
somebody that. Equality of opportunity is a mindless phrase unless you're going to put a lot of money into it. So our governing body put a lot of money into inclusion, more than any other school...it is a very heavy financial investment, and it's a people investment you know, but it works. (Special Education, Teacher, Female)

Investments had been made, for example, to construct the barrier-free environment: this and other concrete actions contributed to making inclusion a reality, rather than mere rhetorical aims and goals, and seemed to have contributed to the students' academic success. As a parent stated,

I think the school does go to extreme lengths to try and cater for all kinds of cases with pupils and they will go down a lot of different avenues to find the right resource to help the person and the family even. There's a lot of extension work that goes on after school hours, weekends, even school holidays...there's an awful lot of work being put in. (Special Education, Parent, Male)

In these schools, then, it appears that the approach to difference among students is regarded as a positive addition to the school community and to the community beyond the school.

\section{Conclusion}

In some respects, the debate on school effectiveness reflects wider debates in social theory around structure and agency. The common criticism of school effectiveness research is that it understates the impact of social structure: in profound ways, schools reflect the communities they serve. Socially, economically and culturally deprived communities are served by inadequate schools because both are the product of social and economic processes which perpetuate inequality and deprivation. This is the view perhaps most trenchantly put by Bowles and Gintis (1976). Advocates of school effectiveness research, by contrast, stress agency (Giddens 1984): governments, schools and teachers are not prisoners of structure, but agents - albeit not entirely free agents - with the capacity to identify and pursue social goals. Schools can change the lives of their students for the better (or worse); if they organise themselves more effectively, they can play an important role in changing the lives of communities in which their students live, as well as of their students as individuals. This is, classically, the perspective of the visionary teacher and educator: that education makes a difference. When viewed in the light of debates about social inclusion, it takes on a particular hue: schools which are effectively geared toward addressing issues of social inclusion and equity can play a key and positive role in promoting equality, in community regeneration, and so forth. 
There are, as we have seen, difficulties with this argument. It is, for example, clear that in order to identify schools as more (or less) 'effective', educational systems must be studded with an array of technologies (widespread measurement and testing of pupils, curricula tightly defined by pre-specified learning outcomes, and the like). There is abundant evidence that these are in some ways damaging to many students, and that they do disproportionately more damage to students from some (typically more socioeconomically deprived) social groups than to others. These problems notwithstanding, this paper has sought to explore the nature of schools which seek to improve the opportunities for students from socially deprived communities, and do so effectively. Our findings are of course provisional, given the small size of our sample of schools. The schools investigated, however, though few in number, were selected as successful schools in challenging circumstances. Within these, the evidence was strong.

For the most part, our conclusions mirror the findings of earlier research on effective schools in socio-economically deprived communities (Hopkins 2001; Joyce et al. 1999; Muijs et al. 2004). In one significant respect, however, we offer something new. This lies in our emphasis of inclusion as an ethos. Schools which seek to serve disadvantaged communities need to engage with those communities. They need to develop values and practices which place inclusion at the centre of what they do, and how they see themselves. This involves many aspects of a school; it no doubt begins with effective and committed leadership (Day et al. 1999; Harris \& Chapman 2001). However, our point is that inclusion has to extend beyond specific strategies and practices, and in particular beyond the leadership and the teachers, to be embraced by the students and their families. This cannot, we suspect, be achieved by a 'quick fix'. Thrupp (1999) emphasised 'the importance of seeing the culture of schools as negotiated with students on the basis of class-related levels of compliance, motivation and "ability" which are ... related to students" views of schooling and their likely occupational futures' (Thrupp 2001: 26). Negotiation with students, and shifting their views of school and occupational opportunity, cannot be achieved by schools alone. Such negotiations inevitably also involve many other parties, of whom students' families are only the most obvious - and perhaps not always the most salient. An ethos of inclusion - permeating the entire school, and in various ways infecting the community it serves - is central to the success of schools seeking to address major problems of social inequality and exclusion. 


\section{References}

Berg, B. (2004), Qualitative research methods for the social sciences ( $5^{\text {th }}$ edn), Pearson, Boston.

Bonell, C., Fletcher, A. and McCambridge, J. (2007), "Improving school ethos may reduce substance misuse and teenage pregnancy", British Medical Journal, Vol. 224 No. 7594, pp. 614-616.

Bowles, S. and Gintis, H. (1976), Schooling in capitalist America; Educational reform and the contradictions of economic life, Basic Books Publishers, New York.

Carrington, B. and Skelton, C. (2003), “Re-thinking 'role models': equal opportunities in teacher recruitment in England and Wales", Journal of Education Policy, Vol. 18 No. 3, pp. 253-266.

Commission of the European Communities (CEC) (1995) Teaching and Learning: Towards the Learning Society. Luxembourg: Office of Official Publications of the European Communities. Available at: http://europa.eu/documents/comm/white papers/pdf/com95 590 en.pdf (accessed 16 January 2009).

Day, C., Sammons, P., Hopkins, D., Harris, A., Leithwood, K., Gu, Q., Brown, E., Ahtaridou, E. and Kington, A. (2009). The impact of school leadership on pupil outcomes. London:

Department for Children, Schools and Families.

Department for Children, Schools and Families (DCSF) (2005), "Pupil Achievement Tracker: Contextually Value Added (CVA) Information", available at: http://www.standards.dcsf.gov.uk/performance/1316367/CVAinPAT2005/?version=1 (accessed 17 November 2008).

Giddens, A. (1984), The constitution of society: Outline of the theory of structuration, University of California Press, Berkeley.

Greenbaum, T. L. (2000), Moderating focus groups: A practical guide for group facilitation, Sage, London.

Harris, A. and Chapman, C. (2001), Leadership in schools facing challenging circumstances. London: Department for Education and Skills.

Hopkins, D. (2001), Meeting the challenge. An improvement guide for schools facing challenging circumstances. London: Department for Education and Skills. 
Includ-ED (2006) "Strategies for inclusion and social cohesion in Europe from education", available at: http://www.ub.es/includ-ed/ (accessed 20 May 2009).

Includ-ED (2008), "Educational practices in Europe: Overcoming or reproducing social exclusion?", available at: http://www.ub.edu/includ-ed/docs/1. D.8.7\%20Report\%203.pdf (accessed 16 October 2009).

Joyce, B., Calhoun, E. and Hopkins, D. (1999). The new structure of school improvement. Buckingham, UK: Open University Press.

Muijs, D., Harris, A., Chapman, C., Stoll, L. and Russ, J. (2004). Improving schools in socioeconomically disadvantaged areas $-A$ review of research evidence. School effectiveness and school improvement, 15(2), 149-175.

Office for National Statistics (2004), “Children's dental health: social factors", available at: http://www.statistics.gov.uk/CCl/nugget.asp?ID=1000\&Pos=1\&ColRank=2\&Rank=224 (accessed 18 April 2008).

Office for National Statistics (2006), "The different experiences of the United Kingdom's ethnic and religious populations", available at:

http://www.statistics.gov.uk/articles/social_trends/ST36_Overview.pdf (accessed 5 April 2008).

Sammons, P. (2007) School Effectiveness and Equity: Making Connections. A review of school effectiveness and improvement research its implications for practitioners and policy makers. Reading: CfBT Education Trust. (Available at:

http://www.cfbt.com/evidenceforeducation/whatweoffer/resources/literaturereviews/scho oleffectiveness.aspx; accessed 10 October 2009)

Scheerens, J. \& Bosker, R. (1997), The Foundations of Educational Effectiveness, Oxford: Pergamon.

Stake, R. E. (1995), The art of case study research, Sage: London.

Stoll, L. and Myers, K. (1998). No quick fixes: Perspectives on schools in difficulty. London: Falmer Press.

Sutton Trust (2005), "Rates of Eligibility for Free School Meals at the Top State Schools", available at:

htp://www.suttontrust.com/reports/RatesOfEligibilityforFreeSchoolMealsattheTopStateSc hools.pdf (accessed 9 December 2008).

Thrupp, M. (1999a). Schools making a difference: Let's be realistic! Buckingham: Open University Press. 
Thrupp, M. (2001) Sociological and Political Concerns about School Effectiveness Research: Time for a New Research Agenda School Effectiveness and School Improvement 12(1), pp. 7-40. 